\title{
Production of a Bacteria-like Particle Vaccine Targeting Rock Bream (Oplegnathus fasciatus) Iridovirus Using Nicotiana benthamiana
}

\author{
Gyeongik Ahn ${ }^{1}$. Joon-Yung Cha ${ }^{1}$. Jeong Won Lee ${ }^{2}$. Gyeongran Park ${ }^{1} \cdot$ Gyeong-Im Shin ${ }^{1} \cdot$ Shi-Jian Song ${ }^{3}$.

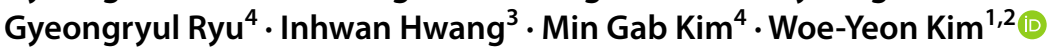

Received: 22 July 2021 / Revised: 31 July 2021 / Accepted: 3 August 2021 / Published online: 28 September 2021

(c) Korean Society of Plant Biologist 2021

\begin{abstract}
Viral diseases are extremely widespread infections that change constantly through mutations. To produce vaccines against viral diseases, transient expression systems are employed, and Nicotiana benthamiana (tobacco) plants are a rapidly expanding platform. In this study, we developed a recombinant protein vaccine targeting the major capsid protein (MCP) of iridovirus fused with the lysine motif (LysM) and coiled-coil domain of coronin 1 (ccCor1) for surface display using Lactococcus lactis. The protein was abundantly produced in $N$. benthamiana in its $N$-glycosylated form. Total soluble proteins isolated from infiltrated $N$. benthamiana leaves were treated sequentially with increasing ammonium sulfate solution, and recombinant MCP mainly precipitated at 40-60\%. Additionally, affinity chromatography using Ni-NTA resin was applied for further purification. Native structure analysis using size exclusion chromatography showed that recombinant MCP existed in a large oligomeric form. A minimum $\mathrm{OD}_{600}$ value of 0.4 trichloroacetic acid (TCA)-treated L. lactis was required for efficient recombinant MCP display. Immunogenicity of recombinant MCP was assessed in a mouse model through enzyme-linked immunosorbent assay (ELISA) with serum-injected recombinant MCP-displaying L. lactis. In summary, we developed a plant-based recombinant vaccine production system combined with surface display on L. lactis.
\end{abstract}

Keywords Bacteria-like particle $\cdot$ Iridovirus $\cdot$ Major capsid protein $\cdot$ Nicotiana benthamiana $\cdot$ Plant-based vaccine

Gyeongik Ahn and Joon-Yung Cha have contributed equally to the work.

\section{Min Gab Kim}

mgk1284@gnu.ac.kr

Woe-Yeon Kim

kim1312@gnu.ac.kr

1 Division of Applied Life Science (BK21 Four), Institute of Agricultural and Life Science, Research Institute of Life Sciences, Gyeongsang National University, Jinju 52828, Republic of Korea

2 Department of Agricultural Chemistry and Food Science and Technology, Gyeongsang National University, Jinju 52828, Republic of Korea

3 Department of Life Science, Pohang University of Science and Technology, Pohang 37673, Republic of Korea

4 College of Pharmacy and Research Institute of Pharmaceutical Science, Gyeongsang National University, Jinju 52828, Republic of Korea

\section{Introduction}

Iridoviridae, a family of double-stranded DNA viruses, consists of five genera: Megalocytivirus, Lymphocystivirus, Ranavirus, Iridovirus, and Chloriridovirus (Williams et al. 2005). In terms of pathogenicity, Megalocytivirus, Lymphocystivirus, and Ranavirus can infect cold-blooded vertebrates such as fish, amphibians, and reptiles, whereas Iridovirus and Chloriridovirus can infect invertebrates, mainly insects (Williams 1996; Chinchar et al. 2002). Megalocytivirus members are widespread in Europe, America, and Asia in both wild and cultured fish populations (Wang et al. 2003). Infection with this virus typically presents symptoms including enlargement of the liver and spleen, darkening of body color, and high morbidity and mortality (Chua et al. 1994; He et al. 2000; Wang et al. 2007; Huang et al. 2012), and outbreaks lead to severe economic losses in the aquaculture industry. Red Sea Bream iridovirus was first isolated in southwest Japan during summer (Shinmoto et al. 2009), and various isolates were subsequently identified such as Rock Bream iridovirus (RBIV), Infectious Spleen and Kidney Necrosis Virus (ISKNV), Turbot Reddish 
Body iridovirus (TRBIV), Dwarf Gourami iridovirus (DGIV), Taiwan Grouper iridovirus (TGIV), and Sea Bass iridovirus (SBIV), all belonging to the genus Megalocytivirus (Chua et al. 1994; He et al. 2000; Murali et al. 2002; Kawakami et al. 2002; Mahardika et al. 2004; Wang et al. 2007; Huang et al. 2012). In Korea, 10 iridoviruses were characterized from four different species of cultured fish, namely Rock bream (Oplegnathus fasciatus), Red sea bream (Pagrus major), Sea bass (Lateolabrax japonicas), and Rockfish (Sebastes schlegeli), during epidemics from 2000 to 2002 (Do et al. 2005). Iridovirus infections typically present symptoms including enlargement of the liver and spleen, darkening of body color, and high mortality (Shimmoto et al. 2010; Liu et al. 2015).

Iridoviruses enter host cells via endocytosis. First, viral DNA is transported to the nucleus and replicated using the host system. After that, virus morphogenesis and capsid assembly take place in the cytoplasm. Depending on the architecture, assembled virions are enclosed by an icosahedral outer protein coat composed of major capsid proteins (MCPs) and minor capsid proteins (Kim et al. 2020a, b). As protein-based vaccines, extracellular surface-exposed proteins are better able to recognize and remove the virus efficiently (Pintilie et al. 2019). Thus, MCPs are important surface antigens and potential candidates for vaccine development.

Although some injectable immunizations are applicable, this method is very stressful to fish and requires significant labor, time, and cost (Shin et al. 2013). To overcome these shortfalls, plant-based vaccine platforms are being explored due to advantages including oral immunization, rapid production, relatively low cost, no risk of contamination by an animal viruses, efficient storage, and easy scale-up (Rybicki. 2014, Park et al. 2016). Plant-based recombinant protein production has been employed to develop vaccines for classical swine fever virus, and seasonal and pandemic flu (Pillet et al. 2019; Park et al. 2021). We recently confirmed that the display of recombinant hemagglutinin-adhesin (HA) proteins of two different AIV strains (H5N6 and H9N2) on the surface of Lactococcus increased the immune response in animals (Song et al. 2021).

In the present study, we aimed to develop a plant-based recombinant vaccine in the form of bacteria-like particles (BLPs) targeting iridovirus using a transient expression system in Nicotiana benthamiana leaves and an antigen delivery platform based on Lactococcus lactis. Furthermore, we characterized the structure of a purified iridovirus MCP and assessed immunogenicity in a mouse model.

\section{Results and Discussion}

\section{Plant-Based Recombinant Vaccine Construction Targeting Major Capsid Protein (MCP) of Iridovirus and Expression in Tobacco Leaves}

A transient tobacco expression system is a powerful and commonly used tool for preparing large amounts of therapeutic proteins (Rybicki. 2014). To develop a vaccine against iridoviruses isolated from cultured fish species in Korea, we generated a construct for the production of MCP of RBIVKOR-TY1 (GenBank accession number AY532606) isolated from Rock bream (Oplegnathus fasciatus) (Do et al. 2005). According to previous reports, recombinant proteins were highly expressed in the endoplasmic reticulum (ER) in plants (Sohn et al. 2018); hence we made a chimeric construct that included a BiP signal peptide and an HDEL ER-retention signal to accumulate large quantities of chimeric protein in the ER. In addition, the lysine motif (LysM) and coiled-coil domain of coronin 1 (ccCor1) were fused with the chimeric protein to explore their effects (Fig. 1a). LysM, a 101 amino acid domain, forms a highly conserved structure consisting of two $\alpha$-helices stacked on two antiparallel $\beta$-sheets, and it binds non-covalently to various types of peptidoglycan and chitin (Visweswaran et al. 2014). Therefore, a single LysM fusion protein binds on the surfaces of L. lactis. As a vaccine delivery system, L. lactis has many advantages including safety and adjuvant-free immunogenicity (Song et al. 2021). Short coiled-coils have been applied to change the topology of engineered proteins, and ccCor1 is a 32-residue coiled-coil domain of the actin-associated protein coronin 1 that plays a role in oligomerization (Kammerer et al. 2005).

To explore whether this recombinant protein is expressed in plants, the fusion construct was transformed into Agrobacterium strain GV3101 and infiltrated into leaf epidermal cells of $N$. benthamiana. In western blotting analysis, fulllength recombinant MCP was detected at $\sim 80 \mathrm{kDa}$ (Fig. 1b) compared with a predicted size of $68 \mathrm{kDa}$ based on the amino acid sequence. In silico prediction revealed that MCP contains six $N$-glycosylation sites at positions $8,237,302$, 311, 398, and 419 (Fig. 1c). Thus, recombinant MCP could appear larger than the predicted size in western blotting.

To confirm the glycosylation state of recombinant $\mathrm{MCP}$, we treated samples with PNGaseF, which removes $\mathrm{N}$-glycans from proteins. SDS-PAGE analysis showed that recombinant MCP bands were decreased in size following PNGaseF treatment to $\sim 68 \mathrm{kDa}$, indicating that recombinant MCP expressed in plants was indeed $N$-glycosylated. Plant-produced $N$-glycosylated antigen enhances vaccine efficacy via balanced multifunctional Th1 $\mathrm{T}$ cell immunity (Kim et al. 2020a, b). Therefore, we expected strong immunogenicity against MCP. 
a

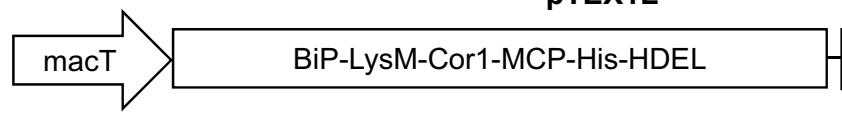

RD29B T

\section{RB}

b

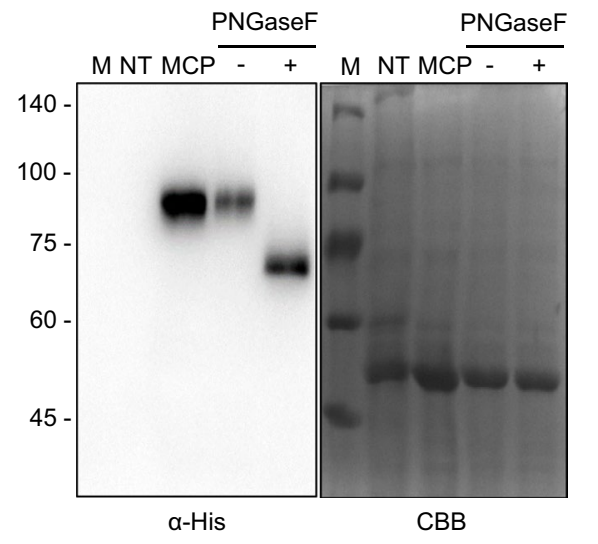

c

MSAISGANVTSGFIDISAFDAMETHLYGGDNAVTYFARETVRSSWY SKLPVTLSKQTGHANFGQEFSVTVARGGDYLINVWLRVKIPSITSS KENSY IRWCDNLMHNLVEEVSVSFNDLVAQTLTSEFLDFWNACMMP GSKQSGYNKMI GMRSDLVGGITNGQTMPAAYLNLPIPLFFTRDTGL ALPTVSLPYNEVRIHFKLRRWEDLLISQSTQADMAISTVTLANIGN VAPALTNVSVMGTCAGLTSEEREVVAQSSRSMLIEQCQVAPRVPVT PVDNSLVHLDLRFSHPVKALFFAVKNVTHRNVQSNYTAAS PVYVNN KVNLPLLATNPLSEVSLIYENTPRLHQMGVDYFTSVDPYYFAPSMP EMDGVMTYCYTLDMGNINPMGSTNYGRLSNVTLSCKVSDNAKTTAA GGGGNGTGYTVAQKFELVVIAVNHNIMKIADGAAGFPIL

\begin{tabular}{rccc}
\hline \multicolumn{1}{c}{ Position } & Potential & Jury agreement & N-Glyc result \\
\hline 8 NVTS & 0.7299 & $(9 / 9)$ & ++ \\
237 NVSV & 0.6787 & $(9 / 9)$ & ++ \\
302 NVTH & 0.5024 & $(4 / 9)$ & + \\
311 NYTA & 0.6401 & $(8 / 9)$ & + \\
398 NVTL & 0.6743 & $(9 / 9)$ & ++ \\
419 NGTG & 0.6626 & $(9 / 9)$ & ++ \\
\hline \multicolumn{5}{c}{} & & (Threshold $=0.5)$
\end{tabular}

Fig. 1 Design of antigen in the form of plant-produced iridovirus MCP vaccine and transient expression in Nicotiana benthamiana. a Schematic view of the BiP-LysM-Corl-MCP-His-HDEL construct. macT, macT promoter; BiP, the leader sequence of BiP; LysM, the first LysM repeat in the cell wall binding domain of AcmA; Cor1, trimerization motif of mouse Coronin 1; MCP, iridovirus major capsid protein; His, hexahistidine tag; HDEL, ER retention signal; RD29B T, RD29B terminator. b Expression levels of recombinant BiP-LysM-Cor1-MCP-His-HDEL proteins in N. benthamiana. Constructs were transiently transformed into leaf epidermal cells of $N$.

\section{Purification of Plant-Produced Recombinant MCP}

To prepare the antigen for immunization, total soluble proteins isolated from infiltrated leaves of $N$. benthamiana were incubated with Ni-NTA resin and eluted by a gradient of imidazole. Recombinant MCP was eluted in 40-100 $\mathrm{mM}$ and $300 \mathrm{mM}$ imidazole fractions (Fig. 2a). However, large amounts of recombinant MCP remained bound to the resin after elution. One possible reason is that recombinant MCP forms a highly oligomeric structure through ccCor1; hence the binding affinity for Ni-NTA resin becomes stronger through the avidity effect.

Ammonium sulfate protein fractionation is helpful for removing debris and unwanted proteins (Park et al. 2015). To apply this technique during purification, total soluble proteins isolated from infiltrated leaves of $N$. benthamiana were treated sequentially with a series of increasing $\left(\mathrm{NH}_{4}\right)_{2} \mathrm{SO}_{4}$ concentrations $(15 \%, 40 \%, 60 \%$, and $80 \%$ saturation). Recombinant MCP was precipitated at $40-60 \%$ and $60-80 \%$ ammonium sulfate $(\sim 66 \%$ and $21 \%$, respectively; Fig. 2b). The $40-80 \%$ ammonium sulfate fraction was dialyzed against phosphate-buffered saline (PBS) and successfully purified by Ni-NTA resin in $250 \mathrm{mM}$ imidazole (Fig. 2c). benthamiana. Total proteins were extracted from infiltrated tobacco leaf tissues and analyzed by SDS-PAGE (right, Coomassie Brilliant Blue-stained gel) and immunoblot analysis using anti-His antibody (left). M, molecular weight standards; NT, non-transformed tobacco leaves; MCP, BiP-LysM-Corl-MCP-His-HDEL-transformed tobacco leaves; $-/+$ PNGase F, with $(+)$ or without $(-)$ peptide- $N$-glycosidase $\mathrm{F}$ treatment of MCP-expressing protein extracts. (c) Prediction of $\mathrm{N}$-glycosylation sites on iridovirus MCP using the NetNGlyc 1.0 server (colored red). Predicted results (threshold $=0.5$ ) are shown below

\section{Purified Recombinant MCP Forms a High Molecular Weight Oligomer}

Oligomerization of recombinant proteins gives rise to increased protein binding affinity through the avidity effect, as well as enhanced stability (Song et al. 2021). This is an advantage for both antigen display on the surface of $L$. lactis and storage. Recombinant MCP contains ccCor1, a short coiled-coil domain. Even though these domains are predicted to form a dimeric structure, many proteins with these domains adopt a trimeric structure (Kammerer et al. 2005). Thus, we analyzed the native structure of purified recombinant MCP using size-exclusion chromatography (SEC). Recombinant MCP proteins were fractionated from about $2000 \mathrm{kDa}$ to about $550 \mathrm{kDa}$ complex and showed the estimated protein peaks at $1436 \mathrm{kDa}$ (Fig. 3). Recombinant MCP monomers are $\sim 80 \mathrm{kDa}$. Therefore, purified MCP proteins formed various oligomers from hexamer to tetracosamer. According to 3D cryo-electron microscopy (cryo-EM) analysis, MCPs of Singapore grouper iridovirus (SGIV) consist of trimers and hexamers (Pintilie et al. 2019). This raises the possibility that our recombinant MCP proteins mimic both the native protein structure and physicochemical behavior in vivo. 

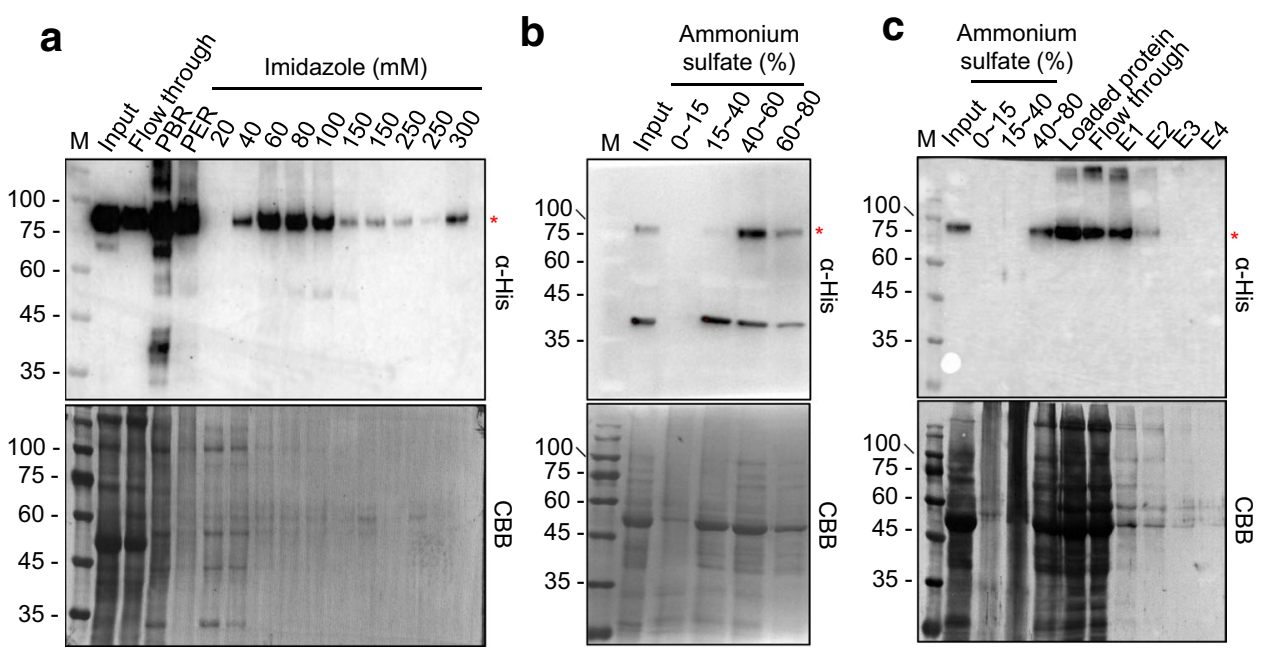

Fig. 2 Purification of plant-produced recombinant MCP proteins. a Affinity purification of plant-produced iridovirus MCP proteins. Protein extracts (input) prepared from infiltrated $N$. benthamiana leaves were loaded onto Ni-NTA resin and eluted by a gradual increase in imidazole concentration. $P B R$ post-binding resin; $P E R$ post-elution resin. b Purification by ammonium sulfate precipitation. Protein extracts (input) were precipitated by a gradual increase in ammonium sulfate concentration. $\mathbf{c}$ Purification using a combined protocol. Total

\section{LysM-Fused Recombinant MCP is Displayed on the $L$. lactis Surface}

L. lactis is Gram-positive lactic acid non-colonizing gut bacterium with generally recognized as safe (GRAS) status awarded by the Food and Drug Administration (FDA) (Song et al. 2017). Therefore, L. lactis is commonly used in various biotechnological applications including metabolite and enzyme production, protein expression, and surface display (Song et al. 2017). As a vaccine delivery vehicle, recombinant MCP is displayed on the surface of L. lactis to form bacteria-like particles (BLPs), but pretreatment with trichloroacetic acid (TCA) and heat is necessary for LysMfused recombinant protein display on the surface of L. lactis (Bosma et al. 2006). To optimize the proper dosage of $L$. lactis, total soluble proteins isolated from infiltrated leaves of $N$. benthamiana were incubated with five concentrations ( $\mathrm{OD}_{600}$ values) of L. lactis; 0.5, 0.4, 0.3, 0.2, and 0.1 (Fig. 4). The amount of antigen displayed increased depending on $L$. lactis concentration and was saturated at $\mathrm{OD}_{600}=0.4$, indicating that this was the minimum concentration of L. lactis required for efficient antigen display.

Recently, L. lactis was engineered as a food-grade strain to produce antimicrobial peptides (Tanhaeian et al. 2020). Therefore, L. lactis is a useful tool for oral delivery systems. In the aquaculture industry, vaccination against infection is generally achieved using needles and syringes. By comparison, oral delivery systems for vaccination are less stressful and more effective in terms of labor, time, and cost (Shin extracts (input) were precipitated by a gradual increase in ammonium sulfate concentration and proteins precipitated at $40-80 \%$ ammonium sulfate concentration (loaded proteins) were purified using Ni-NTA affinity chromatography. E1 to E4, first elution to fourth elution. Proteins were analyzed by SDS-PAGE (bottom, Coomassie Brilliant Blue-stained gel) and immunoblot analysis using anti-His antibody (top). Red asterisks represent iridovirus MCP proteins

et al. 2013). L. lactis-mediated oral delivery systems could be used for the development of protein-based therapeutics as well as a wide range of potential biotechnological applications (Michon et al. 2016).

\section{Recombinant MCP-displayed L. lactis Induces Immunogenicity in Mouse}

To test whether plant-produced MCP displayed on L. lactis acts as a vaccine for pharmaceutical use, we investigated immunogenicity in a mouse model. Three doses $(1,5$, and $10 \mu \mathrm{g}$ ) of MCP displayed on L. lactis were injected into mice twice (first immunization and booster) at 2-week intervals and the $\mathrm{IgG}$ antibody production titer was measured (Fig. 5a). Total sera at 28 days post-infiltration (dpi) were diluted threefold from titers of 100 to 218,700 , and production of antibodies against plant-expressed MCP was analyzed by enzyme-linked immunosorbent assay (ELISA) (Fig. 5b). The MCP-displaying L. lactis-immunized group exhibited a strong ELISA signal in a dose-dependent manner. Since $5 \mu \mathrm{g}$ and $10 \mu \mathrm{g}$ MCP-displaying L. lactis-immunized groups yielded similar signals, $5 \mu \mathrm{g}$ was considered the saturation dose for immunization. In a previous study, a recombinant vaccine-displaying $L$. lactis strain induced a strong immune response even in the absence of adjuvant (Song et al. 2021). L. lactis serves dual roles as a delivery system as well as an adjuvant. This is a huge advantage in efficacy, cost, time, and process simplification. 

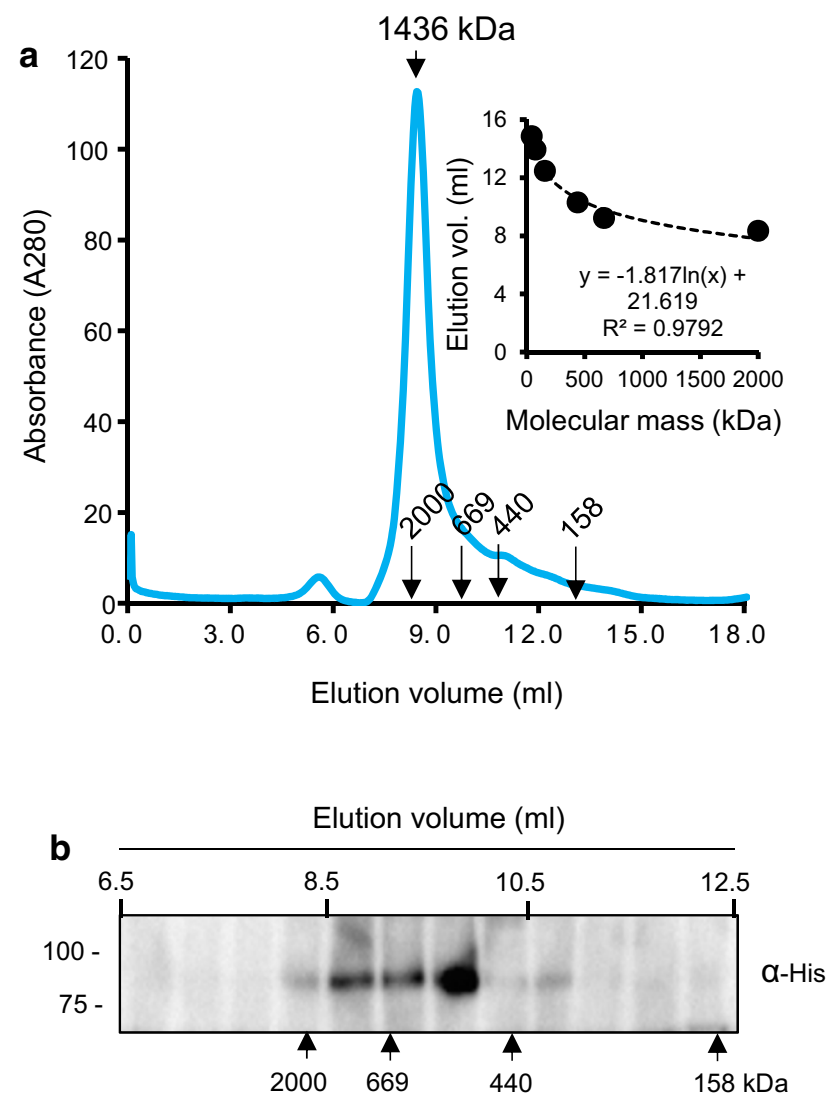

Fig. 3 Size-exclusion chromatography (SEC) of purified recombinant iridovirus MCP. a SEC chromatogram. Purified iridovirus MCP proteins were separated by a Superdex 200 10/300 GL column. Elution volume $(\mathrm{mL})$ is shown relative to protein absorbance at $280 \mathrm{~nm}$ (A280). Molecular masses of known standards (inset) run on the same column are indicated in the chromatogram. b Identification of fractionated iridovirus MCP protein using immunoblot analysis. Fractionated proteins separated by SEC were confirmed by immunoblot analysis using anti-His antibody. Molecular masses of known standards are shown on the left (for SDS-PAGE) and below (for SEC fractions)

\section{Materials and Methods}

\section{Plant Growth Conditions}

Nicotiana benthamiana plants were grown in soil in a growth chamber maintained at $25{ }^{\circ} \mathrm{C}$ and $50 \%$ relative humidity under a $16 \mathrm{~h} \mathrm{light} / 8 \mathrm{~h}$ dark photoperiod with $100 \mu \mathrm{mol}$ photons $\mathrm{m}^{-2} \mathrm{~s}^{-1}$ of cool white fluorescent light.

\section{Plasmid Construction}

The full open reading frame (ORF) encoding the major capsid protein (MCP, AAT71822.1) was isolated from Rock bream iridovirus (Do et al. 2005). The MCP coding sequence was codon-optimized for expression in $N$. benthamiana.

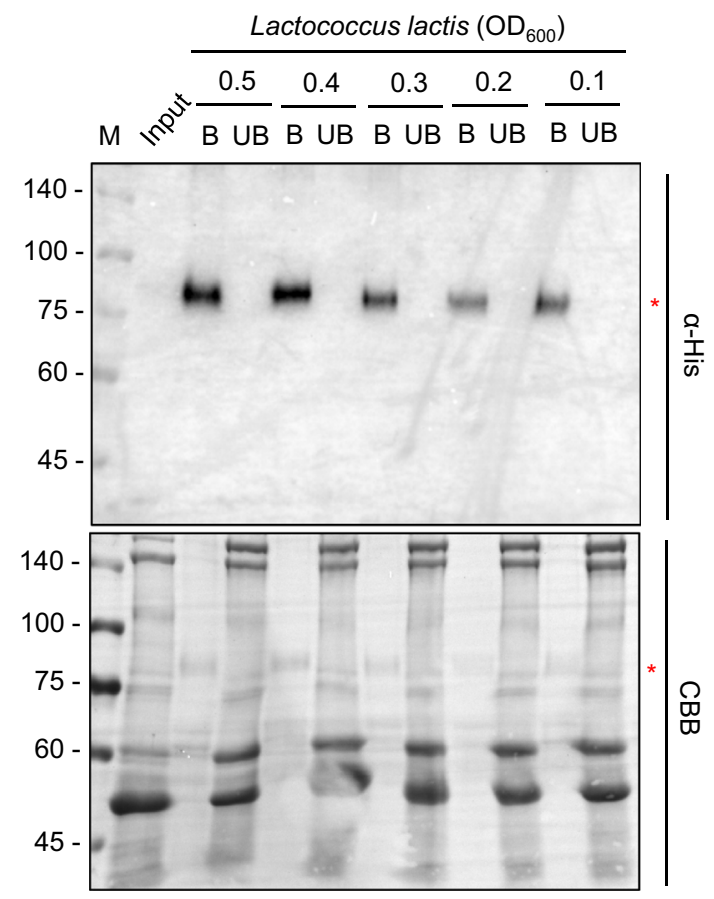

Fig. 4 Specific binding of plant-produced recombinant iridovirus MCP on bacteria-like particles (BLPs). Total protein extracts (input) were incubated with the indicated concentration $\left(\mathrm{OD}_{600}\right)$ of Lactococcus lactis cells. After incubation, the mixture was separated into pellet and supernatant fractions as bound (B) and unbound (UB) proteins, respectively, by centrifugation. These fractions were separated by SDS-PAGE (bottom, Coomassie Brilliant Blue-stained gel) and analyzed by immunoblot analysis using anti-His antibody (top)

\section{Transient Expression of Antigens in N. benthamiana Leaves}

The BiP:LysM:Cor 1:MCP:6xHis:HDEL constructs were transformed into Agrobacterium tumefaciens strain GV3101 by electroporation. Transformed Agrobacterium cells were cultured overnight at $30^{\circ} \mathrm{C}$ in $3 \mathrm{~mL}$ YEP liquid media containing antibiotics, and subsequently sub-cultured overnight in $50 \mathrm{~mL}$ media. Cells were harvested by centrifugation, resuspended in infiltration buffer containing $100 \mathrm{mM} \mathrm{MgCl} 2,100 \mathrm{mM}$ MES, and $100 \mu \mathrm{M}$ acetosyringone to $\mathrm{OD}_{600}=1.0$, and infiltrated into $N$. benthamiana leaves of 3-week-old plant. Tissues were harvested at 3 days after infiltration and frozen in liquid nitrogen. For the deglycosylation, total soluble proteins isolated from infiltrated leaves of $N$. benthamiana were treated with $1 \times$ glycoprotein denaturing buffer and incubated in boiling water for $10 \mathrm{~min}$, and the sample was then chilled on ice. The $15 \mu \mathrm{l}$ denature protein mixed with $2 \mu \mathrm{l}$ GlycoBuffer 2 (10x), $2 \mu \mathrm{l} 10 \% \mathrm{NP}-40$, and $1 \mu \mathrm{l}$ PNGase F and incubated at $37^{\circ} \mathrm{C}$ for $1 \mathrm{~h}$ (NEB, Cat\#P0704S). 

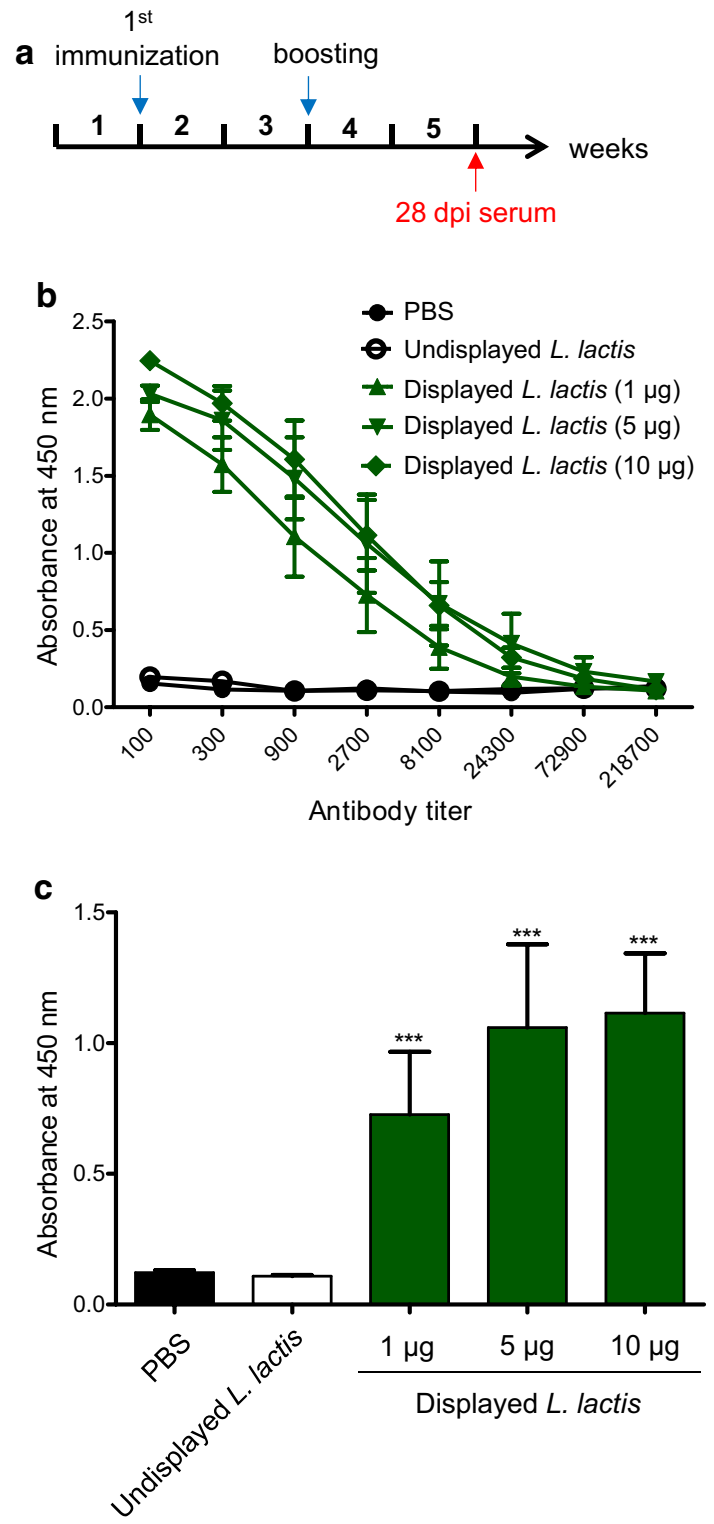

Fig. 5 Immunogenicity of plant-produced recombinant iridovirus MCP-displayed BLPs. a Immunization schedule (dpi, days postimmunization). b Induction of MCP-specific antibody. Twenty five to twenty six-week-old healthy BALB/c mice were randomly divided into five groups. PBS and L. lactis not displaying MCP served as negative control groups. All groups contained four mice. Mice were intraperitoneally injected twice with 1,5 , and $10 \mu \mathrm{g}$ of $L$. lactis displaying MCP as BLPs according to the schedule. Sera were collected 2 weeks after the second injection. Levels of specific antibodies against antigens in serum were analyzed by ELISA after coating with the indicated antigens. c Immunogenicity of coated antigens at a 1:2700 serum dilution ratio. Results are mean \pm standard deviation $(\mathrm{SD} ; n=4)$

\section{Extraction and Purifications of Antigen Proteins}

Total crude proteins were extracted in extraction buffer containing $1 \times$ PBS $(\mathrm{pH} 7.5), 10 \mathrm{mM}$ imidazole, $0.2 \%(\mathrm{v} / \mathrm{v})$
Triton X-100, $1 \mathrm{mM}$ dithiothreitol (DTT), and protease/ proteasome inhibitors. After centrifugation, the resulting supernatant was applied to Ni-NTA Agarose Resin (Qiagen) and incubated at $4{ }^{\circ} \mathrm{C}$ for $4 \mathrm{~h}$. Unbound proteins were removed by washing buffer containing $1 \times \mathrm{PBS}(\mathrm{pH} 7.5)$ and $10 \mathrm{mM}$ imidazole, and His-tagged target proteins were eluted by elution buffer containing $1 \times \mathrm{PBS}(\mathrm{pH} 7.5)$ and imidazole. All proteins were separated by SDS-PAGE. For ammonium sulfate precipitation, total soluble proteins isolated from infiltrated leaves of $N$. benthamiana were treated with a series of increasing ammonium sulfate solutions. The required amount of solid ammonium sulfate was calculated using an online calculator (http://www.encorbio.com/proto cols/AM-SO4.htm). Ammonium sulfate was added slowly with constant stirring for $1 \mathrm{~h}$, samples were centrifuged at $12,000 \mathrm{rpm}$ for $20 \mathrm{~min}$ to precipitate proteins, dissolved in a $1 / 10$ volume of $1 \times \mathrm{PBS}$, and subsequently dialyzed against $1 \times$ PBS at $4{ }^{\circ} \mathrm{C}$ overnight.

\section{Antigen Display on the Surface of $L$. lactis}

Total soluble protein of the infiltrated $N$. benthamiana leaves was extracted by $1 \times$ PBS buffer with $0.1 \%(v / v)$ Triton $\mathrm{X}-100,1 \mathrm{mM}$ EDTA and protease/proteasome inhibitors and centrifuged at $12000 \mathrm{rpm}$ for $20 \mathrm{~min}$. Glycerol (final concentration $25 \%(\mathrm{v} / \mathrm{v}))$ was added in supernatant. L. lactis cells were harvested in stationary phase, washed with $1 \times$ PBS, and resuspended in a $1 / 10$ volume of $10 \%(\mathrm{v} / \mathrm{v})$ TCA at $100{ }^{\circ} \mathrm{C}$ for $30 \mathrm{~min}$. After centrifugation, pellets were washed three times with PBS to remove TCA, incubated with total soluble proteins in incubation buffer comprising PBS, $1 \mathrm{mM}$ EDTA, $0.1 \%$ (v/v) Triton X-100, protease inhibitors, and $25 \%(\mathrm{v} / \mathrm{v})$ glycerol at $37{ }^{\circ} \mathrm{C}$ for $1 \mathrm{~h}$, and washed three times with incubation buffer.

\section{Immunoblot Analysis}

To confirm the target proteins in extraction and purification steps, proteins were separated by SDS-PAGE and transferred onto a polyvinylidene fluoride (PVDF) membrane. Immunoblot analysis was carried using $\alpha$-His monoclonal antibody (Invitrogen; 1:1,000 dilution).

\section{Size-Exclusion Chromatography (SEC)}

Proteins purified by Ni-NTA affinity chromatography were filtered through a $0.2-\mu \mathrm{m}$ filter (Advantec). SEC analysis was performed using an AKTA Fast Performance Liquid Chromatography System with a pre-packed Superdex 200 10/300 GL column (Cytiva). The column was equilibrated with elution buffer containing $50 \mathrm{mM}$ Tris- $\mathrm{HCl}(\mathrm{pH} 8.0)$, $200 \mathrm{mM} \mathrm{NaCl}$, and $0.02 \%$ (w/v) sodium azide, and the injected proteins were fractionated in elution buffer at $8{ }^{\circ} \mathrm{C}$ 
with a flow rate of $0.5 \mathrm{~mL} \mathrm{~min}{ }^{-1}$. Eluted proteins were precipitated in $12.5 \%(\mathrm{v} / \mathrm{v})$ TCA, dissolved in urea/SDS buffer, and confirmed by immunoblot analysis (Van Nguyen et al. 2019). The column was calibrated with molecular mass standards including blue dextran $(2000 \mathrm{kDa})$, thyroglobulin (669 kDa), ferritin (440 kDa), aldolase (158 kDa), conalbumin (76 kDa), and ovalbumin (44 kDa).

\section{Vaccination in Mice}

Female BALB/c mice at 5-6 weeks old (four animals per group) were vaccinated with 1,5 , and $10 \mu \mathrm{g} \mathrm{MCP-displaying}$ L. lactis with a 1:1 volume of complete Freund's adjuvant for the first immunization and incomplete Freund's adjuvant for the booster. PBS and L. lactis not displaying MCP served as negative controls. Blood samples were collected at 28 days post-infiltration.

\section{ELISA of Iridovirus MCP}

The purified plant-expressed BiP-MCP-Cor1-LysM-His protein was coated onto the surface of a 96-well microtiter plate at $4{ }^{\circ} \mathrm{C}$ overnight. After blocking at room temperature with 5\% (w/v) skim milk in TBST buffer for $2 \mathrm{~h}$, mice serum was diluted three-fold from 1:100 with 5\% (w/v) skim milk in TBST buffer and incubated in a microplate for $2 \mathrm{~h}$. After washing three times with TBST, horseradish peroxidase (HRP)-conjugated anti mouse IgG antibody (Invitrogen, Cat\# 32,430, 1:5,000 dilution) was added and incubated for $2 \mathrm{~h}$. After three washes with TBST, TMB substrate (Thermo Fisher, Cat\# 34,025) was added followed by $0.1 \mathrm{M} \mathrm{H}_{2} \mathrm{SO}_{4}$ to stop the reaction. The signal intensity was measured at an absorbance of $450 \mathrm{~nm}$ using multi-microplate readers (Perkin Elmer).

Acknowledgements This work was supported by grants from the National Research Foundation of Korea (project no. NRF2020R1I1A207361012) and by the Next-Generation BioGreen21 Program (SSAC: PJ0159992021) of the Rural Development Administration, Republic of Korea.

Author contribution AG, HI, KMG, and KWY designed the research; AG, CJY, LJW, PG, SGI, SSJ, and RG performed experiments; AG, CJY, HI, KMG, and KWY analyzed data; AG, CJY, KMG, and KWY wrote the manuscript.

\section{Declarations}

Conflict of interest The authors have no competing interests to declare.

Ethical approval Animals were housed in accordance with ethical principles and experimental procedures to minimize animal suffering following a protocol approved by the Institutional Animal Care and Use Committee (IACUC) of Gyeongsang National University (GNU200331-M0017).

\section{References}

Bosma T, Kanninga R, Neef J, Audouy SA, van Roosmalen ML, Steen A, Buist G, Kok J, Kuipers OP, Robillard G, Leenhouts K (2006) Novel surface display system for proteins on non-genetically modified gram-positive bacteria. ASM 72(1):880-889. https://doi.org/10.1128/AEM.72.1.880-889.2006

Chinchar VG (2002) Ranaviruses (family Iridoviridae): emerging cold-blooded killers. Arch Virol 147(3):447-470. https://doi. org/10.1007/s007050200000

Chua FHC, Ng ML, Ng KL, Loo JJ, Wee JY (1994) Investigation of outbreaks of a novel disease, 'Sleepy Grouper Disease', affecting the brown-spotted grouper, Epinephelus tauvina Forskal. JFD 17:417-427. https://doi.org/10.1111/j.1365-2761.1994. tb00237.x

Do JW, Cha SJ, Kim JS, An EJ, Park MS, Kim JW, Kim YC, Park MA, Park JW (2005) Sequence variation in the gene encoding the major capsid protein of Korean fish iridoviruses. Arch Virol 150(2):351-359. https://doi.org/10.1007/s00705-004-0424-6

He JG, Wang SP, Zeng K, Huan ZJ, Chan SM (2000) Systemic disease caused by an iridovirus-like agent in cultured mandarinfish, Siniperca chuatsi (Basilewsky), in China. J Fish Dis 23:219222. https://doi.org/10.1046/j.1365-2761.2000.00213.x

Huang Z, Tang J, Li M, Fu Y, Dong C, Zhong JF, He J (2012) Immunological evaluation of Vibrio alginolyticus, Vibrio harveyi, Vibrio vulnificus and infectious spleen and kidney necrosis virus (ISKNV) combined-vaccine efficacy in Epinephelus coioides. Vet Immunol Immunop 150(1-2):61-68. https://doi. org/10.1016/j.vetimm.2012.08.008

Kammerer RA, Kostrewa D, Progias P, Honnappa S, Avila D, Lustig A, Winkler FK, Pieters J, Steinmetz MO (2005) A conserved trimerization motif controls the topology of short coiled coils. PNAS 102(39):13891-13896. https://doi.org/10.1073/pnas.0502390102

Kawakami H, Nakajima K (2002) Cultured fish species affected by red sea bream iridoviral disease from 1996 to 2000. Fish Pathol 37:45-48

Kim A, Yoon D, Lim Y, Roh HJ, Kim S, Park CI, Kim HS, Cha HJ, Choi YH, Kim DH (2020a) Co-expression network analysis of spleen transcriptome in rock bream (Oplegnathus fasciatus) naturally infected with rock bream iridovirus (RBIV). Int J Mol Sci 21(5):1707. https://doi.org/10.3390/ijms21051707

Kim H, Kwon KW, Park J, Kang H, Lee Y, Sohn EJ, Hwang I, Eum SY, Shin SJ (2020b) Plant-produced $N$-glycosylated Ag85A exhibits enhanced vaccine efficacy against mycobacterium tuberculosis HN878 through balanced multifunctional Th1 T cell immunity. Vaccines 8(2):189. https://doi.org/10.3390/vaccines8020189

Liu HI, Chiou PP, Gong HY, Chou HY (2015) Cloning of the Major Capsid Protein (MCP) of Grouper Iridovirus of Taiwan (TGIV) and preliminary evaluation of a recombinant MCP vaccine against TGIV. Int J Mol Sci 16(12):28647-28656. https://doi. org/10.3390/ijms161226118

Mahardika K, Zafran Yamamoto A, Miyazaki T (2004) Susceptibility of juvenile humpback grouper Cromileptes altivelis to grouper sleepy disease iridovirus (GSDIV). Dis Aquat Organ 59(1):1-9. https://doi.org/10.3354/dao059001

Michon C, Langella P, Eijsink VG, Mathiesen G, Chatel JM (2016) Display of recombinant proteins at the surface of lactic acid bacteria: strategies and applications. Microb Cell Fact 15:70. https://doi.org/10.1186/s12934-016-0468-9

Murali S, Wu MF, Guo IC, Chen SC, Yang HW, Chang CY (2002) Molecular characterization and pathogenicity of a grouper iridovirus (GIV) isolated from yellow grouper, Epinephelus awoara (Temminck and Schlegel). J Fish Dis 25:91-100

Park SR, Lim CY, Kim DS, Ko K (2015) Optimization of ammonium sulfate concentration for purification of colorectal cancer 
vaccine candidate recombinant protein GA733-FcK isolated from plants. Front Plant Sci 6:1040. https://doi.org/10.3389/ fpls.2015.01040

Park Y, Oh Y, Wang M, Ganges L, Bohórquez JA, Park S, Gu S, Park J, Lee S, Kim J, Sohn E (2021) A novel E2 glycoprotein subunit marker vaccine produced in plant is able to prevent classical swine fever virus vertical transmission after double vaccination. Vaccines 9(5):418. https://doi.org/10.3390/vaccines 9050418

Park KY, Wi, SJ (2016) Potential of plants to produce recombinant protein products. Journal of Plant Biology 59(6):559-568. https:// doi.org/10.1007/s 12374-016-0482-9

Pillet S, Couillard J, Trépanier S, Poulin JF, Yassine-Diab B, Guy B, Ward BJ, Landry N (2019) Immunogenicity and safety of a quadrivalent plant-derived virus like particle influenza vaccine candidate-Two randomized Phase II clinical trials in 18 to 49 and $\geq 50$ years old adults. PLoS One 14(6):e0216533. https://doi.org/ 10.1371/journal.pone.0216533

Pintilie G, Chen DH, Tran BN, Jakana J, Wu J, Hew CL, Chiu W (2019) Segmentation and comparative modeling in an 8.6- $\AA$ Cryo-EM map of the Singapore Grouper Iridovirus. Structure 27(10):1561-1569.e4. https://doi.org/10.1016/j.str.2019.08.002

Rybicki EP (2014) Plant-based vaccines against viruses. Virol J 11:205. https://doi.org/10.1186/s12985-014-0205-0

Shimmoto H, Kawai K, Ikawa T, Oshima S (2010) Protection of red sea bream Pagrus major against red sea bream iridovirus infection by vaccination with a recombinant viral protein. Microbio Immunol 54(3):135-142. https://doi.org/10.1111/j.1348-0421.2010.00204.x

Shin YJ, Kwon TH, Seo JY, Kim TJ (2013) Oral immunization of fish against iridovirus infection using recombinant antigen produced from rice callus. Vaccine 31(45):5210-5215. https://doi.org/10. $1016 /$ j.vaccine. 2013.08 .085

Shinmoto H, Taniguchi K, Ikawa T, Kawai K, Oshima S (2009) Phenotypic diversity of infectious red sea bream iridovirus isolates from cultured fish in Japan. Appl Environ Microbiol 75(11):3535-3541. https://doi.org/10.1128/AEM.02255-08

Sohn EJ, Lee Y, Park N, Park M, Kim NH, Park S, Min K, Gu S, Park Y, Song J, An DJ, Hwang I (2018) Development of plantproduced E2 protein for use as a green vaccine against classical swine fever virus. J Plant Biol 61:241-252. https://doi.org/10. 1007/s12374-018-0133-4

Song AA, In L, Lim S, Rahim RA (2017) A review on Lactococcus lactis: from food to factory. Microb Cell Fact 16(1):55. https://doi. org/10.1186/s12934-017-0669-x

Song SJ, Shin GI, Noh J, Lee J, Kim DH, Ryu G, Ahn G, Jeon H, Diao HP, Park Y, Kim MG, Kim WY, Kim YJ, Sohn EJ, Song CS, Hwang I (2021) Plant-based, adjuvant-free, potent multivalent vaccines for avian influenza virus via Lactococcus surface display. J Integr Plant Biol. https://doi.org/10.1111/jipb.13141. Advanceonlinepublication.10.1111/jipb.13141

Tanhaeian A, Mirzaii M, Pirkhezranian Z, Sekhavati MH (2020) Generation of an engineered food-grade Lactococcus lactis strain for production of an antimicrobial peptide: in vitro and in silico evaluation. BMC Biotechnol 20(1):19. https://doi.org/10.1186/ s12896-020-00612-3

van Nguyen B, Lee DW, Lee S, Hwang I, Cheong GW (2019) Structural Analysis of Tha4 a Twin-arginine Translocase Protein Localized in Plant Thylakoid Membranes. Journal of Plant Biology 62(2):129-136. https://doi.org/10.1007/s12374-018-0373-3

Visweswaran GR, Leenhouts K, van Roosmalen M, Kok J, Buist G (2014) Exploiting the peptidoglycan-binding motif, LysM, for medical and industrial applications. Appl Microbiol Biot 98(10):4331-4345. https://doi.org/10.1007/s00253-014-5633-7

Wang CS, Shih HH, Ku CC, Chen SN (2003) Studies on epizootic iridovirus infection among red sea bream, Pagrus major (Temminck and Schlegel), cultured in Taiwan. J Fish Dis 26(3):127-133. https://doi.org/10.1046/j.1365-2761.2003.00441.x

Wang YQ, Lü L, Weng SP, Huang JN, Chan SM, He JG (2007) Molecular epidemiology and phylogenetic analysis of a marine fish infectious spleen and kidney necrosis virus-like (ISKNVlike) virus. Arch Virol 152(4):763-773. https://doi.org/10.1007/ s00705-006-0870-4

Williams T (1996) The iridoviruses. Adv Virus Res 46:345-412. https://doi.org/10.1016/s0065-3527(08)60076-7

Williams T, Barbosa-Solomieu V, Chinchar VG (2005) A decade of advances in iridovirus research. Adv Virus Res 65:173-248. https://doi.org/10.1016/S0065-3527(05)65006-3 